\title{
О СМЫСЛЕ ЖИЗНИ, ЖИЗНЕННЫХ ЦЕЛЯХ И ИСТОЧНИКАХ СЧАСТЬЯ
}

\begin{abstract}
А. Н. Хвостиченко
К. в. н., доцент

главный редактор «Альманаха «Онтология и жизнь»

Всемирное научное ноосферно-онтологическое общество,

В статье предлагается ноосферно-онтологический подход к отночению и формированию наиболее значимых для человека понятий смысл жизни и жизненные иели, понимание счастья и его источников. Опираясь на работы А. Маслоу, его последователей и авторские исследования представлена пирамида жизненных потребностей человека, и на этой основе сформулированы обобщенные группы жизненных иелей с выходом на смысл жизни через японское понятие Икигай. Также кратко проанализированы основные составляющие состояния счастья человека, источники радости и духовные чувства.
\end{abstract}

Ключевые слова: смысл жизни, иели жизни, счастье, потребности, радость, чувства, идеаль, вера.

Цель данной статьи - предложить наиболее общие подходы к определению человеком смысла жизни, своих жизненных целей и источников счастья на основе ноосферно-онтологической теории мыслетворчества В. П. Бабича [1].

Люди по-разному относятся к своей жизни. Если спросить человека: «Каков смысл вашей жизни, ради чего вы живете?», - то обнаружится, что многие даже не задумываются об этом: «Не знаю, живу и живу...». Кто-то скажет: «Я живу ради того-то... (семьи, детей, внуков, др.)». Очень редко можно услышать: «У меня есть миссия, я реализую свое предназначение и т. п.».

Если человек понимает, зачем он живет, ради чего, чувствует, насколько это важно для него, то у него есть значимые мотивы, чтобы жить. Чем больше у человека значимых целей, тем больше у него причин продолжать жить на Земле. Он гордится своими целями, может о них рассказать, потому что для него это важно.

Если же человек не знает для чего живет, запутался в жизни, то ему скучно живется, он выживает в суете повседневных дел. Его преследуют скука и безразличие, они переходят в апатию, потом в депрес- 
сии. Такой человек долго на Земле не задерживается - у него нет смысла жизни.

Каждый человек - индивидуальность, у каждого - свой багаж знаний и опыта, неповторимое окружение, условия, ситуации. Слепое копирование чужого опыта (как и целей) в своей жизни, в своих ситуациях вряд ли приведет к желаемым результатам. Важно понять общие принципы, закономерности, следование которым приведет к решению задачи. А примеры из опыта разных людей - подтверждения тому, усиливающие уверенность в себе - раз кто-то смог, то и я смогу.

Говоря о самом важном в жизни человека, следует проанализировать общие жизненные потребности, чтобы понимать и себя, и других. Ведь для любого человека самое важное у каждого свое, и в разные моменты времени оно может меняться. Кому-то важно купить машину (и именно Мерседес, и только такой-то модели, цвета, т. п.). Кому-то жизненно необходимо новое жилье. Кому-то поправить здоровье. А на фоне острой зубной боли гаснут вообще все проблемы мира... И это понятно. Но важно также понять общие практически для всех людей задачи, которые мы решаем по жизни.

Что же это могут быть за цели? Ответы будут разные в зависимости от развитости человека, уровня развития его души $[2,3,4,5]$. Для человека первого уровня самым важным будут материальные ценности. Он будет ставить себе соответствующие цели: квартира, дом, дача, машина чтобы все было крепкое, добротное, на века... Человеку второго уровня мало жить в достатке, для него важнее эстетичность, чтобы все было красиво до изысканности, ему нужны чувственные удовольствия во всем. На третьем уровне человек начинает ценить духовные качества, гармонию, покой, силу, достоинство. Даже в бизнесе такой человек ищет партнеров не столько с материальной выгодой, сколько людей чести, от которых он может обогатиться прежде всего духовно, общением с которыми он будет гордиться. Для человека четвертого уровня самое ценное - это истина, больше всего он ценит знания, легко работает с информацией. ${ }^{1}$

В соответствии со своими ключевыми ценностями - что для человека самое важное - он ставит перед собой соответствующие цели. По целям можно судить, что за человек перед вами.

1 Такая градация развития людей разработана М. Ю. Дюкаревым. Наиболее подробно с раскрытием соответствующих психотипов людей разного уровня развития предлагает Е. А. Сокальская в своем авторском методе энергетических матриц [5]. 
В пятидесятых годах двадцатого столетия Абрахам Маслоу [6, 7, 8] классифицировал все основные потребности человека, которые движут человеком по жизни, и предложил модель, названную в последствии пирамидой Маслоу. На сегодняшний день эта теория получила различные интерпретации, дальнейшее развитие и предлагается автором в следующем виде (рис. 1).

«Я совершенно убежден, что человек живет хлебом единым только в условиях, когда хлеба нет. Но что случается с человеческими стремлениями, когда хлеба вдоволь и желудок всегда полон? Появляются более высокие потребности, и именно они, а не физиологический голод, управляют нашим организмом. По мере удовлетворения одних потребностей возникают другие, все более и более высокие. Так по-

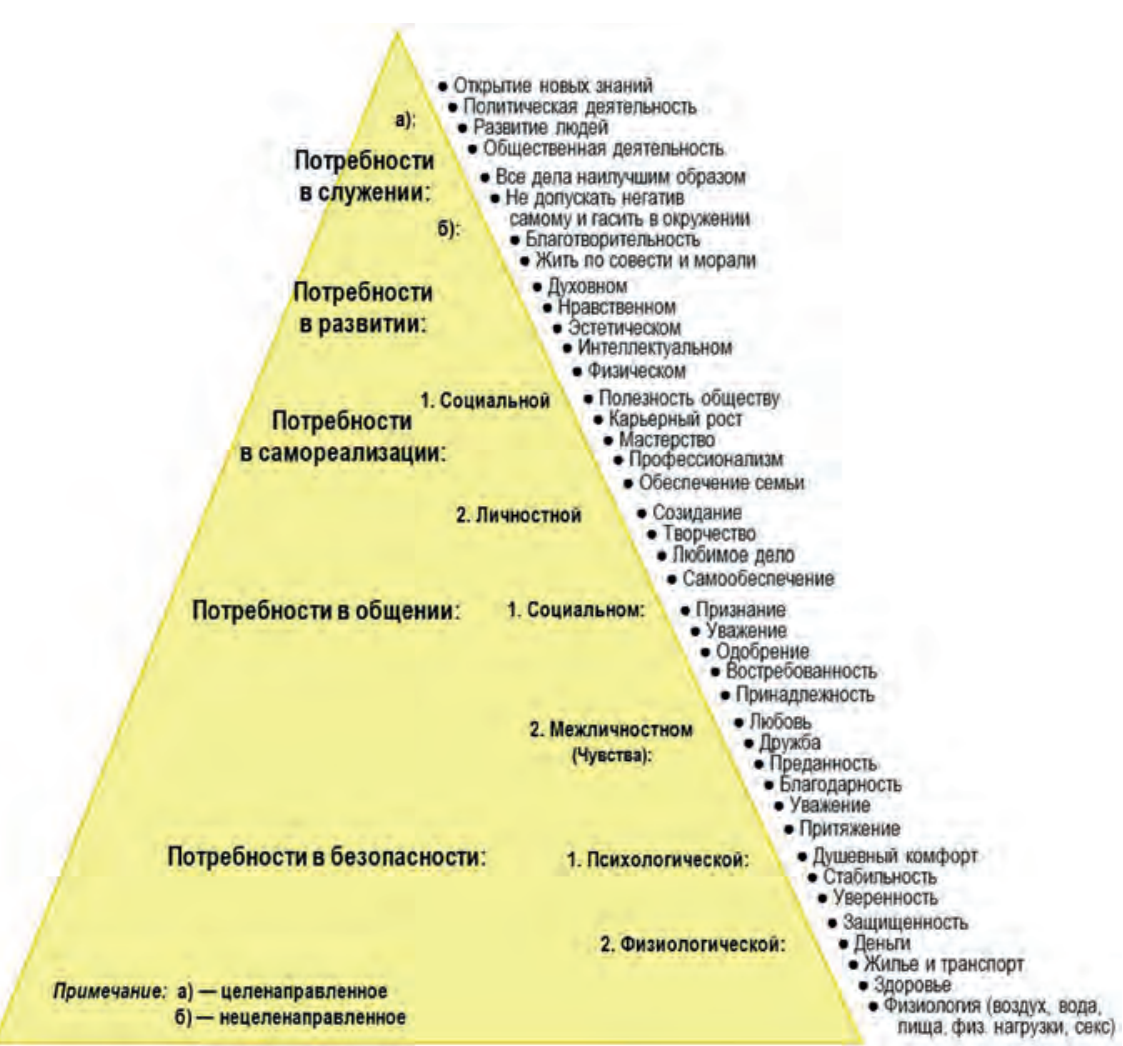

Рис. 1. Пирамида потребностей 
степенно, шаг за шагом человек приходит к потребности в саморазвитии - наивыстей из них». А. Маслоу.

Маслоу распределил потребности по мере возрастания. Он объяснил это тем, что люди не могут испытывать потребности вышестоящего уровня, пока не решены более примитивные задачи. В основании - физиология (утоление голода и жажды, секс, сон и т. п.). Ступенью выше - потребность в безопасности и т. д. Важно отметить, что каждая из потребностей не обязательно должна быть утолена полностью - достаточно частичного насыщения для перехода на следующую ступень.

Это реально можно наблюдать в жизни. Кто-то живет только мыслями, суть которых выжить любой ценой. Кто-то живет задачами спасения Мира (экология, др.). Кто-то где-то между ними. Кто-то, реализуя верхние потребности, может и не уделяет должного внимания нижерасположенным потребностям, но их «заброшенность» делает человека несчастным или как минимум уязвимым. Так гениальный талант в творчестве может быть несчастным в личной жизни или иметь серьезные проблемы со здоровьем, т. д. С другой стороны, можно зависнуть на двух нижних уровнях бесконечно улучшая качество питания, комфорт проживания и т. д., зациклиться на вопросах безопасности.

Если обобщить эти потребности и перевести их в цели, то можно сформировать следующую пирамиду основных групп целей (рис.2).

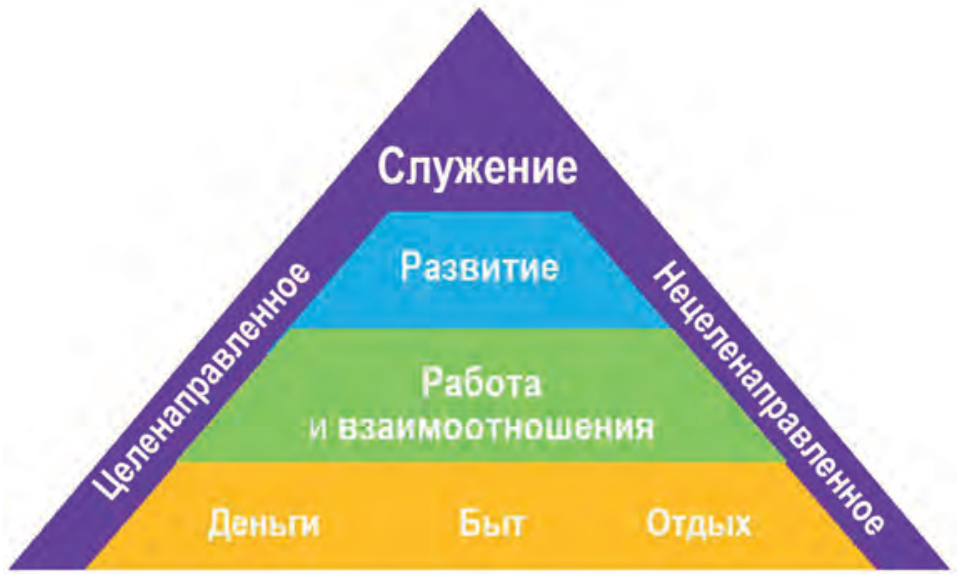

Рис. 2. Пирамида целей 
Фундамент пирамиды составляют цели, связанные с деньгами, бытом и отдыхом. Выше - этаж из целей по работе и взаимоотношениям. Над ними - цели по развитию, как условию для реализации всех целей. И на вершине - цели по служению: природе (экология), обществу (социально-политические проекты), людям (благотворительность). В идеале - цели по служению и их реализация должны пронизывать все остальные цели, всю жизнь. К этому человек приходит не сразу, а по мере своего духовного роста.

Таким образом цели должны охватывать все основные сферы жизни, чтобы жизнь была гармоничной, полноценной, без перекосов и провалов. В каждой из указанных сфер жизни цели могут быть текущими, долгосрочными и жизненными (на всю жизнь).

Так или иначе человек задается вопросом «А в чем же смысл жизни и моей в частности?». Это происходит на этапе духовного созревания. Сначала человек пытается постичь вопрос «Кто Я?». Из него вырастает вопрос «Для чего Я?». От правильности ответов на эти вопросы зависит вся дальнейшая судьба человека.

Если Я — только тело, и от меня после смерти ничего не останется, то часто срабатывает программа «живем один раз», и тогда нужно взять от жизни все для удовлетворения личных удовольствий. Тогда человек становится эгоистом и вступает в постоянную конкурентную борьбу за выживание, где по идее выигрывает только сильнейший. Но ведь всегда может найтись кто-то более сильный чем вы. Тогда — крах всей жизни.

Если же Я - прежде всего Душа, созданная Высшими силами (Богом) для бесконечной жизни, то отношение к жизни на Земле выстраивается совсем другое. Тогда жизнь наполняется Благодарностью к тем, кто создал душу и прекрасную окружающую природу, а также к тем, кто дал тело и подготовил к самостоятельной жизни. Тогда жизнь приобретает высший смысл, который ведет человека к реализации своего предназначения, наполняя человека радостью, счастьем - тем, что в Японии называется одним словом «Икигай» [9].

Японское понятие Икигай не имеет однозначного перевода. Суть перевода этого слова на русский язык - то, что придает жизни смысл и то, что заставляет нас просыпаться каждое утро с радостью, главный интерес жизни, то дело, которое приносит радость в нашу жизнь. 
Именно интерес к жизни, желание немедленно приступить к своему делу и выполнить его самым лучшим образом, дает людям ощущение собственной значимости, чувство удовлетворенности и смысл жизни.

Вполне логично, что тем людям, которые знают свой Икигай, незнакомы депрессии, они сохраняют оптимистическое отношение к жизни и не подвержены деструктивным привычкам. Поэтому для каждого человека, который хочет прожить долгую и осмысленную жизнь, так важно найти для себя причину вставать по утрам.

На схеме (рис. 3) показаны «лепестки цветка» Икигай, отражающие основополагающие посылы для определения Икигай. «Цветок» отражает методологию для поиска Икигай каждым человеком через определение для себя содержания лепестков (внешний круг), затем их парных пересечений (средний круг), это дает понимание их тройных пересечений (внутренний круг) и в целом понимание индивидуального Икигай. Эта схема помогает разобраться человеку во многих важных понятиях и найти для себя конкретные ответы для внесения в свою жизнь и смысла, и счастья.

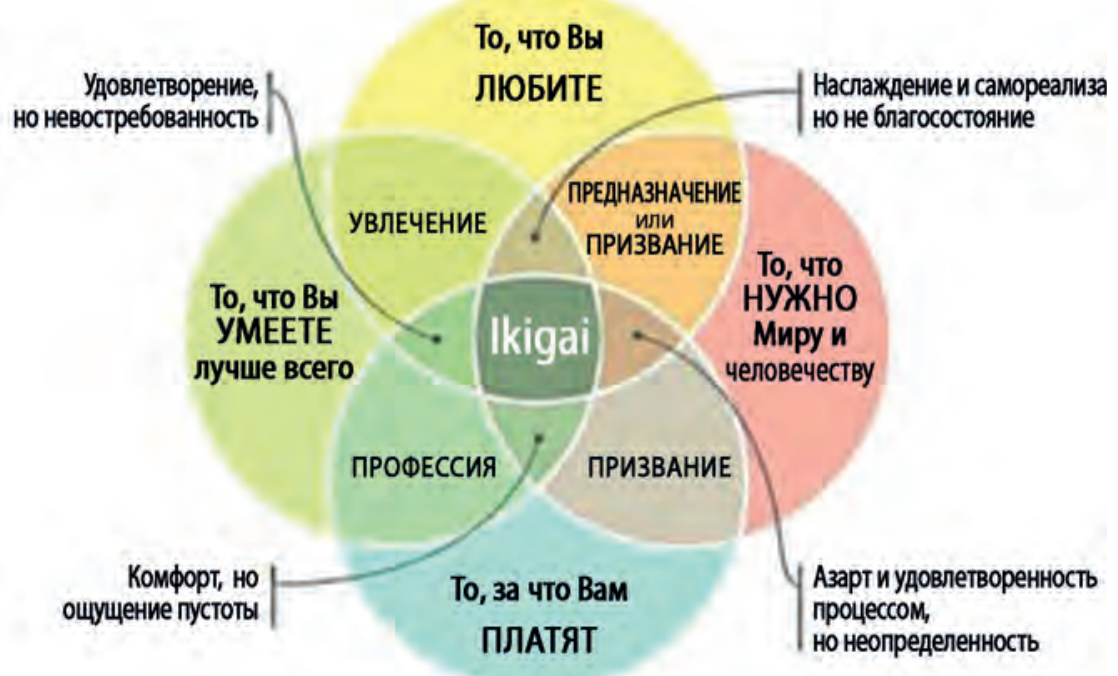

Рис. 3. Лепестки цветка Икигай 
Жизненные цели напрямую связаны с источниками радости основы состояния счастья $[10,11]$.

По сути источники радости - это все позитивное, что может быть в жизни человека, и их желательно раскрыть максимально полно. Источники радости можно объединить в две группы: внутренние - отношение, настрой, здоровье и внешние - работа, взаимоотношения, отдых, творчество, служение. Рассмотрим их немного подробнее.

Внутренние.

Отношение - доброжелательное, адекватное, уважение, благодарность, любовь - к себе, другим, к окружающему миру, к Высшим силам - понимание и пробуждение чувств, идеалов и веры. Дают покой (уверенность, возможность концентрироваться на самом важном, и сосредотачивать свои силы на главном), создают условия для высоких состояний. Вместо самоуничижения и гордыни, зависти, обид, ненависти - энергетическое саморазрушение, противодействие, неприятные ситуации, болезни. т. п.

Настрой - опора на позитив, самомотивация, вера в себя, в успех, др. - дают наполненность энергией, внутреннюю готовность к созиданию и при необходимости к защите, воодушевление, хочется жить и творить. Вместо уныния, сомнений, неверия, озлобления - блокируют стремления, достижение целей, развитие.

Здоровье - профилактика, правильное питание, здоровый образ жизни, физическая культура - дают энергичность, работоспособность. Лучшее здоровье - то, которого не замечают. Вместо болезненности, обесточенности, физических ограничений.

Внешние.

Работа - общественно полезная, интересная, перспективная, хорошо оплачиваемая, в идеале любимая - дает удовлетворение, гордость, развитие, карьерный рост и достойные доходы - на работу как на праздник. Вместо монотонности, однообразности, ненавистности, вредности для общества, опасности для здоровья, малооплачиваемости, т. П. - на работу как на каторгу.

Взаимоотношения - личные, семейные, дружеские, трудовые, пр.- комфортное общение, притяжение, уважение, благодарность, преданность, дружба, любовь - все лучшее, что может быть между людьми довести до мастерства, дает уверенность, радость до восхищения. Вместо одиночества, склок, обид, зависти, ненависти, т. п. - 
обесточивают, разрушают энергетически, открывают энергетическим воздействиям.

Отдых - регулярно в ритмах и традициях, интересно, разнообразно - уединение, общение, походы, праздники, экскурсии, путешествия - дает восстановление душевных и физических сил, массу позитивных эмоций, впечатлений, воспоминания о которых поддерживают в повседневности. Вместо истощенности, замученности, дивана с ТВ, усугубляемых вредными привычками.

Творчество - прежде всего сценическое искусство (танцы, вокал, театр, юмор) и другие виды искусств - пробуждают интерес к жизни, дают мощный заряд энергии, вдохновение, восторг, позволяют переносить состояние творчества в повседневную деятельность. Вместо обыденности, рутинности, безрадостности, др.

Раскрытие этих источников и дает состояние счастья, когда радость становится непреходящей (то больше, то меньше), а причин для страданий не остается.

Работа по раскрытию источников радости, собственно, и является содержанием развития личности - наращивать мастерство во всем в деятельности, в общении и т. п. Алгоритм здесь един, как и в любой профессиональной сфере:

понимание $\rightarrow$ принятие $\rightarrow$ навыки $\rightarrow$ опыт $\rightarrow$ мастерство.

По каждому из обозначенных направлений развития существует множество методик, курсов, тренингов - вопрос лишь в их эффективности - скорости движения к желаемым результатам могут быть разными, но в любом случае результат будет зависеть от количества и качества вложенных усилий.

Источниками наиболее высоких состояний счастья являются чувства ${ }^{1}$, идеалы и вера. С одной стороны, человек может формировать их осознанно - создать условия пробуждения, найти ответы на множество вопросов. С другой, - сами чувства, вера, идеалы - это дар богов, это энергия, которая входит в сердце и освещает мысли и по-

1 Здесь речь идет о духовных чувствах в отличие от физиологических ощущений, воспринимаемых известными органами чувств. Также автор отличает от чувств негативные и другие эмоции (реакции психики на раздражители) такие как страх, вина, гордость/гордыня, и мн. др., часто ошибочно называемое чувствами.

Приводимые здесь описания даются на основе содержания занятий авторских курсов формирования личности М. Ю. Дюкарева (Миание). 
ступки человека. Это энергия, которая входит и начинает жить в сердце человека. Если человек этим дорожит, правильно себя ведет, то огонь в сердце нарастает (крылья растут).

Энергия чувств, идеалов и веры позволяют человеку не только испытывать высокие состояния, чувствовать прекрасное, красоту, гармонию, т. п., а и по ощущениям понимать, когда он поступает правильно и неправильно, то или не то делает. Потому что резко повышается порог чувствительности и различения добра и зла. Когда он делает то - сердце его горит, поет, когда не то - радость пропадает.

Чувства дают огромный прилив жизненной энергии - кажется, горы сможешь свернуть, и крылья за спиной вырастают - человек почти летает и светится радостью. При правильном отношении энергия раскрывается и делает человека все сильнее. При неправильном — она может угаснуть частично или совсем, и человек может лишиться чувств.

Чувства - это дар, высшая награда за правильное отношение и развитие взаимоотношений [4]. Считается, что чувства нужно заслужить, а получив, логично дорожить ими.

Основные чувства - притяжение, уважение, дружба, любовь. Усиливающие и не менее важные - благодарность и преданность.

Притяжение - возникает между людьми как начальное чувство (может как испытательное - насколько человек способен ценить чувства). Возникает как внешне не объяснимое влечение одного человека к другому, радость от общения. Во что вырастет это чувство зависит от человека.

Уважение - чувство к человеку, превосходящему какими-то качествами, способностями или общим уровнем развития - позволяет быть открытым (возможность учиться у него, подчиняться с чистой совестью).

Дружба - как чувство возникает между равными $(\approx, \pm)$, чтобы люди могли получать радость от общения, готовности прийти на помощь и попросить помощи самому.

Любовь - прекрасное чувство любви между мужчиной и женщиной. В основе любови - стремление делать все для счастья любимого человека. Человек ощущает, как его сердце вспыхивает. Экстрасенсы могут видеть в это время, какая энергия входит в сердце, как от сердца к сердцу идет поток света. И чем сильнее чувства, тем мощнее этот 
поток. Есть и другой показатель. Если чувства сильные, то образ (фантом) избранника(-цы) постоянно сопровождает человека. И если раньше, к примеру, девушка прогуливалась и постоянно слышала комплименты, предложения, то, когда появился образ любимого - все прекратилось (подсознательно мужчины видят сигнал - занято, нет шансов).

Любовь - универсальное чувство, имеет несколько разновидностей, кроме как между мужчиной и женщиной. Есть любовь к родителям, к детям. Есть братская любовь, когда человек испытывает глубокие чувства к близким по духу, к прошедшим бок о бок не один год через различные испытания. Они все различны по своей природе, но они соединяют сердца, для того чтобы человек мог почувствовать сердцем это шанс, это награда, это благословлено Богом. Любовь — это дар. Невозможно в равной степени любить всех живущих на Земле. Есть круг ближайших людей, и к ним могут быть самые сильные чувства, которые нужно заслужить, выстроить. Если человек к этому стремится, то рано или поздно он это заслуживает - это прекрасные состояния.

Благодарность - искусство отвечать добром, усиливает любые взаимоотношения.

Преданность — чувство, вызывающее максимальное доверие к человеку, на него можно положиться во всем.

Некоторые люди хотят облегченных отношений, не обремененных обязательствами - сегодня с одним, завтра с другим. Они не заслуживают чувств. Каждая встреча — как зарубка на сердце. К концу Пути что вспомнить - сиюминутные встречи? Чувствам нужно пройти определенный путь, решить массу задач, чтобы сердце пело, и от человека исходило сияние. Для этого взаимоотношения должны быть всерьез и надолго. Это серьезная большая работа, но это и высшая награда - у человека за спиной крылья вырастают.

Второй источник высших состояний - это идеаль, это понимание как идти по жизни правильно. Как Вселенная хочет, чтобы я поступал в той или иной ситуации? Если человек следует идеалам, то они дают ему энергию ходить с высоко поднятой головой, дают силу и право не прятать взгляд и иметь пламенное сердце. Это огромное чувство радости, удовлетворения - я занимаюсь важным достойным делом, я поступаю правильно. В то же время идеалы предупреждают: «Наверное, я что-то сделал не так, - что-то беспокойно на душе». 
Основные идеалы - любви, добра, справедливости, силы (ненасилия), красоты, гармонии, созидания, иерархии [4].

Человек без идеалов, с пустым сердцем этого чувствовать не может. Хорошо сделал, плохо - ничего не чувствует. Его душа бедна. Внутри пустыня. Душа не поет, не играет.

Идеалы, воплощенные в жизни, - это совесть, понимание справедливости, уверенность, что человек идет по жизни так, как нужно, и понимание всего, что делает не так (можно изменить, исправить ошибки).

Вера - это также энергия, которую дает Бог — это дар. По сути вера - признание истинности убеждений (существования Бога, др.), подтверждаемых чувством в сердце, т. е. откликом особой энергии в сердце. Именно это чувство (огонь в сердце) и является самым сильным аргументом для человека верующего. Не путать с фанатизмом, там чувств нет, там духовная болезнь, заавтомаченность.

В любой религии, эзотерической школе чтобы впустить Бога в свое сердце, нужно помолиться, обратиться с просьбой. Высшие силы определяют, что человек настроен правильно, и тогда в него входит Бог. Человек ощущает: входит энергия, в сердце что-то происходит входит божья благодать, льются слезы радости и очищения, др. В человека входит вера и преображает его.

Человеку, имеющему массу проблем и неадекватных представлений о Боге, неправильно давать огромные по силе чувства, огромную по силе веру. Человек получает какую-то веру изначально, а дальше это его длинный путь развития. И каждая новая ступень, новое представление, убеждение, приближающее человека к истине, к Богу, открывает новые грани ощущений, более сильные переживания.

В обществе существует масса ложных стереотипов, нагнетающих туман невежества вокруг рассмотренных понятий. Опираясь на общечеловеческие ценности, на секулярную духовность, каждый человек может найти свой жизненный путь, обрести полноценное счастье. Для этого необходимы цель, знания, стремление, вера в себя и активность.

\section{Литература}

1. Прикладная онтология: монография / В. П. Бабич, В. А. Могилко, В. М. Онегина. - Харьков: Изд-во «Типография Мадрид»,2013. — 364 с. 
2. Миание М. Ю. Философия Космоса. - Харьков: Созидание, 2007. - 128 с.

3. Миание М. Ю. Сознание человека. - Харьков: Созидание, 2007. - 192 с.

4. Миание М. Ю. Законы Творца. - Харьков: Созидание, 2008. - 368 с.

5. Сокальская Е. А. Типы Энергетических Матриц. 2018. https:/www. youtube.com/watch? $\mathrm{v}=\mathrm{IXSAUY} 6 \mathrm{hzHc}$

6. Maslow A. H. Motivation and Personality. - New York: Harpaer \& Row, 1954.

7. Маслоу А. Х. Мотивация и личность. - С-Пб: Питер, 2014. - 400 с.

8. Маслоу А. Х. Дальние пределы человеческой психики. - С-Пб: Питер, 2016. - $448 \mathrm{c}$.

9. Моги Кен. Икигай. Смысл жизни по-японски / переводчик В. В. Степанова. - М.: КоЛибри, 2018. - 192 с.

10. Миание М. Ю., Потемкина А. Г. Счастье. - Харьков: Созидание, 2011. $240 \mathrm{c}$.

11. Практический курс счастья / Дж. Кехо; пер. с англ. С. Борич. — минск: Поппури, 2015. - 128c. 